\title{
Analysis on Sichuan College Students' Segmental Phoneme Errors
}

\author{
Chuandong $\mathrm{Ma}^{1 *}$, Lunhua $\operatorname{Tan}^{2}$ \\ ${ }^{1}$ College of Fundamental Education, Sichuan Normal University, Chengdu, China \\ ${ }^{2}$ Sichuan Science and Technology University for Employees, Chengdu, China \\ Email: *machuandong2006@163.com \\ Received March 26 $6^{\text {th }}, 2013$; revised April 27 $7^{\text {th }}, 2013$; accepted May $7^{\text {th }}, 2013$
}

Copyright (C) 2013 Chuandong Ma, Lunhua Tan. This is an open access article distributed under the Creative Commons Attribution License, which permits unrestricted use, distribution, and reproduction in any medium, provided the original work is properly cited.

\begin{abstract}
The negative transfer of mother tongue has a big influence on the students in Sichuan when they learn English pronunciation. Based on the contrast analysis and error analysis theory, this paper analyzes the recordings of students' oral English test and summarizes the errors the students make when they learn the segmental phonemes: 1) Students use phonemes in Sichuan dialect to take place those similar in English; 2) Students confuse nasal consonant [n-] with lateral consonant [1-]; 3) Students find it difficult to distinguish ending consonants [-n] and [- $\eta]$; 4) A lot of students can not pronounce [r] correctly; 5) Few of the students pay attention to the quality differences of long vowels and short vowels; 6) Many students mispronounce the combinations of consonants $[f, v, s, z, r, h, k, g]+[i, i:] ; 7)$ In $[s+p / t / k]$ combination, students give a strong aspiration for $[\mathrm{p} / \mathrm{t} / \mathrm{k}] ; 8$ ) Students like to add a vowel sound in the consonant clusters; 9) They sometimes add a vowel after the ending consonants.
\end{abstract}

Keywords: English Pronunciation; Segmental Phoneme; Language Transfer; Error Analysis; Contrast Analysis

\section{Introduction}

The contrast analysis and error analysis hypothesis were put forward in the 1950s (Fries \& Lado) based on the transfer theory, which insists that mother tongue habits would influence foreign language acquisition, that is, language transfer, defined by linguists. It is positive transfer, if the learner's native language helps in learning the second language, otherwise, the negative transfer (Wang, 1990). Despite the conflicting views on the significance of language transfer in historical linguistics, the notion of language transfer remained uncontroversial among language teachers into the twentieth century. As early as the schools of the ancient world, teachers were writing down contrastive observations about the languages students knew and the languages they wished to learn (Kelly, 1969). And as recently as the schools are fluenced by figures such as Sweet (1899, 1972), Jespersen (1912), Palmer (1917), Fries (1945), and other proponents of new (or seemly new) methods of language teaching, there is a widespread acceptance of the idea that native language influence could greatly influence second language acquisition (Odlin, 2001), especially when learning the pronunciation (Ellis, 1994). Chinese is categorized into SinoTibetan family while English belongs to Indo-European family, thus they differ greatly in all aspects. From the prospective of language acquisition, the lack of social and family language learning environment leads to the negative transfer rather than the positive one.

English as the second language had not been taught in most

\footnotetext{
${ }^{*}$ Corresponding author.
}

of the middle schools in China until 1957. Most learners begin to learn English from the first year in middle school (Ke, 1986), so they miss the best time for learning the second language, that is from 6 to 12. The Chinese sound system, grammatical system and syntax have already rooted in their knowledge long before they get contact with the second language, English. Some linguists believe that language acquisition is a process of getting into habits, not that of learning. If learners drill repeatedly in listening, speaking, reading and writing, they would gradually master the second language. But the result goes against the prediction of the theorists. According to Full-time Six Years Middle School Teaching Plan, the required time for English learning is: 960 hours for arts majors, five hours per week; 932 hours for science majors, five hours per week in the first two years, and in the last year, four hours per week (Ke, 1986). The Chinese students in fact spend a lot of time in learning English before entering colleges, and they are excellent in writing and reading comprehension, but very poor in oral English, especially the students from Sichuan dialect area. Due to mother tongue's negative transfer, students' poor pronunciation seriously influence their spoken English and their listening comprehension.

Segmental phoneme is one of the most important factors to distinguish meanings in English. Due to mother tongue's transfer, lot of students in Sichuan dialect area makes mistakes when they speak English. Based on contrast analysis and error analysis theory, this paper analyzes their segmental phoneme errors in their pronunciation and the reasons so as to give some hints to language teachers in dialect areas. 


\section{Sichuan Dialect Sound System}

Sichuan dialect usually refers to the official dialect used by the natives in Sichuan Province, Chongqing Municipality and nearby areas. According to the classification in The Atlas of Chinese Languages (1987-1990) ${ }^{1}$, Sichuan dialect belongs to the south-west official dialect. Besides the official dialect in Sichuan and Chongqing, there are some other non official dialects, such as, "Tu-gong-dung-va", another name for "Hak-kava", and "Old Hu-Guang Words" of "Xiang Dialect" (Cui, 1996), but the speakers can easily communicate with each other in Sichuan Dialect.

Sichuan dialect is characteristically "foreign exclusive". In its system, the sounds, vocabulary and grammar are mostly in agreement, and the inhabitants have little difficulty in communication, but there remains some discrepancies because of the wide geographical distribution and cultural diversity of their speakers. In this paper, we take the dialect popular in Chengdu and Chongqing areas as the research subject.

\section{Differences between Sichuan Dialect and English in Their Sound Systems}

English belongs to Indo-European languages, while Chinese belongs to Sino-Tibetan languages, so they differ from each other greatly in their sound systems.

1) Differences in phonemes

There are nine consonants and ten vowels in English in the same family phonemes with those in Sichuan dialect, and the others are completely different:

a) The manners and the places of articulation for most of the consonants are different in the two languages. In Sichuan Dialect, there are two sets of blade affricates: [ts, ts, tş, tş] and one set of palatal [t, t , ], but in English, there is a set of post-alveolar fricative) [ , , ] and two dentals [ , ].

b) In English, there are 8 counterparts of voiceless and voiced consonants, they are: [ , ], [ , ], [ , ], [ , ], [ , ], $[],,[$,$] , while in Sichuan dialect there are 5$ counterparts of aspirated and unaspirated consonants, they are: [ , ], $[],,[],,[\mathrm{ts}, \mathrm{ts}],[\mathrm{t}, \mathrm{t}]$. In English, when a consonant is pronounced, whether the vocal cord is vibrated or not (voiced or voiceless) distinguish the meaning of words. For example, put and but are different not only in pronunciation but also in meaning, because phoneme [ ] is voiceless and [ ] is voiced, even if the other phonemes in these two words are completely the same. In Sichuan dialect, voiced or voiceless is not a distinctive feature, but whether a consonant is aspirated or not is very important for distinguishing word meaning. For example, when we pronounce the word “波 bō", whether we vibrate our vocal cord or not, the meaning of the word “波” does not change, but if the consonant "b" is aspirated, “波 bō" changes into “坡 pō", another word with different meaning. In English, whether a consonant is aspirated or not does not distinguish meaning. For example, in such words as sky, student and sport, letters " $\mathrm{k}, \mathrm{t}, p$ " should be voiceless and unaspirated according English pronunciation rules, but even if one pronounces them as [sp t] or [ ] or [ ], the others would not misunderstand him. In Sichuan dialect, most consonants are voiceless, and there are only six voiced: [ ,

, , , , ].

c) There are more single vowels in English than those in Sichuan dialect. In English, there are twelve single vowels and in Sichuan dialect only ten. The length of articulation and the degree of tense of the speech organ are the distinctive features in English. For example, bit [ ] and beat [ ] are two different words, but in Sichuan dialect, in word “妈 mā”, the length of the vowel would not change the meaning of word, while the tone pitch does. Example: mā(妈), má(麻), mă(马), mà (骂).

d) There are more diphthongs and triphthongs in Sichuan dialect than in English. There are nineteen diphthongs and triphthongs in Sichuan dialect, and in English there are eight diphthongs no triphthongs in true sense (Xu, 1985).

2) Differences in sound combinations

a) The sound combinations in the two languages differ greatly. In English, consonant clusters are very common. For example, spring, plate, degree. And the position of most consonant clusters are free in a word. They can appear at the beginning, in the middle or at the end of a word. Except for consonant [ ], all the other ones can appear at the beginning; Except for [ , , ,

], the others can appear at the end. But in Sichuan dialect, there is no consonant cluster. Only one consonant is allowed to appear at the beginning of a word and consonants never appear in the middle of a word. Not like that in English, there are only two consonants [ , ] can appear at the end of a single word.

b) Most consonants in English can be freely combined with vowels, except for [ , , ] with some vowels. But in Sichuan dialect, the consonant and vowel combinations are much more restricted and many consonants can not be combined with some vowels, for example, [ , , , , , ] never goes together with vowel [ ].

\section{Analysis on the College Students' Segmental Phoneme Errors}

We conducted a oral English test on 98 students from different areas of Sichuan in September, 2011. Most of them are second year students and only five of them are third year students from one university in Chengdu. They were first required to read a passage with correct pronunciation and intonation, and then to talk about a topic. Their reading and speaking were recorded. After the tests, we analyzed their recordings and collected the data. Based on their reading and our analysis, we summarize their errors in phonemes and sound combinations as follow and their supra-segmental errors will be analyzed in another paper.

1) Errors in phonemes.

a) They often use phonemes in Sichuan dialect to take place those similar in English.

Fricatives [ , ] for dentals [ , ]. Example: think [ ] ${ }^{* 2}$, this []$^{*}$;

Fricatives [ , ] for [ , ]. Example: shine [ ] ${ }^{*}$,pleasure []$^{*}$;

Affricates [ ] for [ , Example: China [ $]^{*}$, jean []$^{*}$;

Semi-vowel [ ] for [ ]. Example: very [ ];

Vowel [ ] for [ ] or [ ]. Example: back [ ] , but [ ] *;

b) They always confuse nasal consonant [ - ] with lateral consonant [ - ].

In Sichuan dialect, [ -] and [ -] belong to the same phoneme,

${ }^{1}$ Chinese Languages Atlas, China Academy of Social Sciences and Australian Academy of Humanlity, 1987/1990. Hongkong Langman publishing co., LTD.

${ }^{*}$ :for wrong pronunciation. 
in another word, they are appophones, some what like " $p$ " in pot and " $p$ " in spot in English. Therefore, it is very common to hear the students pronounce name as [ $]^{*}$, or like as [ ] *.

c) They find it difficult to distinguish [- ] and [- ].

When [- ] and [- ] appear at the end of a word, there are six combinations in Sichuan dialect:

$[-\quad],[-],[--],[-],[-],[-]$, among which only [- ] and [- ] are distinguishing phonemes in Sichuan dialect, for example, ānquán (安全), āngzhāng (肮脏). There are not [- $]$ and [- $]$ in its sound system. That is why so many students find it difficult to distinguish such words as sing, thing, rang, song from sin, thin, ran and son.

d) A lot of students can not pronounce [ ] correctly.

Phoneme [ ] in English is defined as a voiced post alveolar fricative. The sound is articulated between the tip of the tongue and the back part of the teethridge. When the air passes over air passage, the soft palate is raised, the lips are rounded and the vocal cords are made to vibrate. In most regions of Sichuan dialect area, there is not such a sound, and only in some places there is a similar sound [ ], but the lips are not rounded. When students meet the words like read, right etc., they pronounce them either as []$^{*}$ and []$^{*}$, or [ $]^{*}$ and [ $]^{*}$.

e) Few of the students pay attention to the quality differences of long vowels and short vowels.

The length of articulation and the tense degree of muscle do not distinguish meanings in Sichuan dialect, while in English they are very important distinctive features. There are four sets of vowels different in length in English, they are: [ , ], [ ,

], [ ]. [ ]. They do differ from each other in length, or in "quantity", but at the same time, they differ in "quality" (Gimson, 1970, p.103). Generally speaking, the short vowels in English are articulated shorter and the muscle of the speech organ, is less tense, but for the long ones, it is longer and more tense, therefore, the openings of the mouth for the long vowels are bigger and the front part of tongue is lower. Students in Sichuan can easy distinguish them in length, but they usually neglect their differences in quality. Example: in the word bit, [ ] is short and relaxed, but many students make it too tense and close, which sounds like the shortened [ ].

2) Errors in sound combinations

a) Errors in C (consonant) + V (vowel) combinations

Many students mispronounce the combinations of consonants [f, v, s, z, r, h, k, g] + [ , ]. In Sichuan dialect, [f, , s, $\mathrm{z}, \mathrm{r}, \mathrm{h}, \mathrm{k}, \mathrm{g}]$ never appear before close vowels $[$,$] , and the$ smallest close vowel following these consonants are [ ], so they tend to pronounce words like fill, veil, silk, zero, real, hill, kill, give as [ $]^{*},[]^{*},[]^{*},[\mathrm{l}]^{*},\left[\begin{array}{ll}{ }^{*} \text { or } \\ \text {, }\end{array}\right.$ [ ] $]^{*},[]^{*},[]^{*}$ and []$^{*}$.

b) In $[\mathrm{s}+p / \mathrm{t} / \mathrm{k}]$ combination, students give a strong aspiration for $[p / \mathrm{t} / \mathrm{k}]$.

According to English pronunciation rules, when $[p, \mathrm{t}, \mathrm{k}]$ fol- low an initial [s], they are realized with no aspiration even when stressed (Gimson, 1970: p. 48). It is a redundant feature in English which does not discriminate meanings of words. Example, [ ] in word sport, [ ] in student and [ ] in sky are unaspirated. Many students usually pronounce them with a strong aspiration: [ ] $]^{*},[]^{*},[\mathrm{]}]^{*}$, which sounds really odd.

c) They like to add a vowel sound in the consonant clusters.

Consonant clusters are very common in English, but never in Sichuan dialect (see Part III). When they read words with consonant clusters like: br-, bl-, pr-, pl-, kr-, kl-, gr-, gl-, sr-, sl-, thr-, spl-, spr-, skr-, -pl- etc., they ususlly add a vowel sound between the consonants. Examples: please [ ] ${ }^{*}$, employ []$^{*}$, three []$^{*}$. Sometimes, they add a vowel sound in the ending clusters. Example: bags [ ] ${ }^{*}$.

d) They sometimes add a vowel after the ending consonants.

In Sichuan dialect, only [- , - ] appear at the ending position, and the others all at the beginning, followed by vowels. There are many open syllables ending in vowels. Students are used to ending a syllable with a vowel. When they meet the words ending in consonants in English, unconciously they like to add a vowel after the consonant. Example: sit []$^{*}$ or []$^{*}$, bad []$^{*}$, take $[\quad]^{*}$.

\section{Conclusion}

Judging from the analysis above, we are convinced of that language transfer, to be precise, the negative transfer of mother tongue does exist when learners learn a foreign language, especially when learning the pronunciation. It is evident that the differences in the sound systems between Sichuan dialect and English give great difficulties to the students, as is showed above. We hope our analysis could give some hints to language teachers in dialect areas if it's useful.

\section{REFERENCES}

Cui, R. C. (1996) Sichuan dialect and bashu culture, Chapter Three. Sichuan official language. Chengdu: Sichuan University Press.

Gimson, A. C. (1970). An introduction to the pronunciation of English (2nd ed). London: Latimer Trend \& Co. Ltd.

Fries, C. C. (1962). Teaching and learning English as a foreign Language. Ann Arbor: University of Michigan Press.

Wang, C. M. (1990). Applied psycholinguistics. Changsha: Hunan Education Press.

O'Connor \& Arnold (1961). Intonation of colloquial English (2nd ed). Longman.

Ellis, R. (1999). The study of second language acquisition. Shanghai: Shanghai Foreign Languages Education Press.

Odlin, T. (2001). Language transfer. Shanghai: Shanghai Foreign Languages Education Press.

Xu, T. F., Yu , X. M., \& Sun, W. B. (1985). Modern English phonetics. Xi'an:Shanxi People Publishing House. 